\title{
PENYUSUNAN ZONA KONSERVASI DAN PEMANFAATAN AKUIFER BEBAS PADA CEKUNGAN AIRTANAH PAGATAN KABUPATEN TANAH BUMBU, KALIMANTAN SELATAN
}

\author{
Agus Harjanto ${ }^{1}$, Thomas Triadi Putranto ${ }^{2}$ and Widyanto David²
}

Diterima: 8 Juni 2018

Disetujui: 29 Mei 2019

\begin{abstract}
Abstrak: Wilayah cekungan airtanah Pagatan yang berada di Kabupaten Tanah Bumbu, Provinsi Kalimantan Selatan memiliki luas wilayah sebesar $506.714 \mathrm{Ha}$ atau 13,5\% dari total luas Provinsi Kalimantan Selatan. Bertambahnya jumlah penduduk menjadikan kebutuhan akan air bersih juga terus bertambah. Sebagai salah satu sumber terbaik untuk air bersih, airtanah terus diambil secara intensif untuk memenuhi kebutuhan air bersih. Pengambilan airtanah ini menjadi tidak terkontrol berdampak menurunnya kuantitas dan kualitas dari airtanah. Tujuan penelitian ini adalah untuk mengetahui pola aliran airtanah, mengetahui kualitas airtanah, mengetahui batas penentuan zona konservasi, dan daerah yang harus dilindungi, dan kesesuaian perencanaan tata ruang wilayah dengan peta zona konservasi daerah penelitian. Metode yang digunakan adalah metode observasi dan metode analisis. Metode observasi yaitu melakukan pengukuran muka air tanah, dan pengambilan sampel sumur gali, sedangkan metode analisis yaitu pengolahan data yang dilakukan berdasarkan data primer dan sekunder yang didapat pada data lapangan penelitian untuk menentukan zona konservasi dan pemanfaatan airtanah pada akuifer bebas di daerah penelitian. Hasil penelitian menunjukkan muka airtanah akuifer bebas memiliki pola aliran airtanah cenderung menyebar ke arah timur dan ke arah selatan. Dari 150 sampel airtanah terdapat 9 sampel yang tidak memenuhi syarat untuk keperluan air minum. Pembangunan zona konservasi air tanah didasarkan pada faktor ketersediaan air tanah, kesamaan kerusakan air tanah.
\end{abstract}

\begin{abstract}
Pagatan groundwater basin is located on Tanah Bumbu Regency, South Kalimantan Province with $506.714 \mathrm{Ha}$ or $13,5 \%$ from South Kalimantan total area. The increasing of population also affect the water demand as a human primary need. This groundwater extraction has been turning uncontrollaby and decreasing the quantity and quality of groundwater. The purpose of this study is to know the water tables, to know the quality of groundwater, to determine the category of conservation zone and areas to be protected, and suitability of spatial planning of the region with conservation zone of research area. The method for this research is qualitative observation and descriptive. The method of observation is the measurement of water table, and sampling of wells, data processing which is done based on primary and secondary data obtained on field research data to determine the zone of conservation and groundwater utilization in in research area.The result showed that unconfined groundwater aquifers have groundwater flow pattern spreading flow towards South and Southwest. From the 150 groundwater samples, there are 9 samples that do not meet the requirements for drinking water.The construction of groundwater conservation zone is based on groundwater availability factor, the similarity of groundwater damage.
\end{abstract}

Keywords: Pagatan groundwater basin, unconfined aquifer, conservation zone

\footnotetext{
${ }^{1}$ Departemen Teknik Geologi Fakultas Teknologi Mineral UPN Veteran Yogyakarta

${ }^{2}$ Departemen Teknik Geologi Fakultas Teknik Universitas Diponegoro
} 


\section{PENDAHULUAN}

Cekungan airtanah (CAT) Pagatan terletak di Provinsi Kalimantan Selatan mempunyai luas $6441 \mathrm{Km} 2$ yang secara administratif berada pada tiga kabupaten, yaitu Kabupaten Tanah Laut, Kabupaten Kota Baru dan Kabupaten Tanah Bumbu (PERMEN ESDM No. 2 Tahun 2017). Cekungan ini merupakan sumber utama kebutuhan airtanah yang ada pada ketiga kabupaten tersebut.

Wilayah CAT Pagatan yang berada di Kabupaten Tanah Bumbu memiliki luas wilayah sebesar $5.067 \mathrm{~km} 2(506.714 \mathrm{Ha})$ atau 13,5\% dari total luas Provinsi Kalimantan Selatan yang terdiri dari sepuluh kecamatan. Jumlah penduduk Kabupaten Tanah Bumbu sebesar 334.314 penduduk pada akhir tahun 2016 (BPS Kabupaten Tanah Bumbu, 2016). Dengan bertambahnya jumlah penduduk menjadikan kebutuhan akan air bersih juga terus bertambah. Semakin bertambahnya kebutuhan air bersih dapat menyebabkan pengambilan airtanah ini menjadi tidak terkontrol, sehingga dapat menyebabkan menurunnya kualitas dan kuantitas dari airtanah.

Pemanfaatan air yang berlebihan dan penggunaan air yang tidak terarah dapat menyebabkan pencemaran dan penurunan kualitas dan kuantitas airtanah, mengurangi daya dukung airtanah dan mengganggu keseimbangan sistem hidrologi. Salah satu akibat terganggunya keseimbangan sistem hidrologi adalah menurunnya kemampuan infiltrasi akibat penggunaan tataguna lahan yang tidak tepat sehingga terbentuk penurunan muka airtanah (Todd, 1980). Apabila ekploitasi airtanah dilakukan secara berlebih akan menyebabkan terjadinya amblesan tanah (Chang dkk., 2017). Tujuan penelitian ini adalah untuk mengetahui pola aliran airtanah, mengetahui kualitas airtanah, mengetahui batas penentuan zona konservasi, dan daerah yang harus dilindungi, dan kesesuaian perencanaan tata ruang wilayah dengan peta zona konservasi daerah penelitian.

Pembuatan zona konservasi dan pemanfaatan airtanah dibutuhkan agar airtanah dapat dimanfaatkan secara maksimal. Hal ini dilakukan untuk meningkatkan pemulihan atau pengisian airtanah dan membantu mengurangi tingkat penurunan tingkat airtanah (Rao dan Yang, 2010).

\section{Geologi Dan Hidrogeologi Regional}

Kabupaten Tanah Bumbu secara stratigrafi termasuk dalam Cekungan Barito. Cekungan Barito merupakan lingkungan pengendapan batubara delta. Menurut Satyana dan Silitonga (1994), pada mulanya Cekungan Barito dan Cekungan Asam-asam adalah suatu cekungan yang sama, tetapi pengangkatan Pegunungan Meratus pada periode Miosen Awal menyebabkan cekungan tersebut terpisah menjadi dua cekungan. Daerah cekungan airtanah (CAT) Pagatan termasuk dalam Lembar Peta Geologi Banjarmasin (Sikumbang dan Heryanto, 1994).

Geologi regional pada daerah penelitian bersifat kompleks dibuktikan dengan adanya antiklin, sinklin, sesar naik, sesar mendatar, dan sesar turun. Sikumbang dan Heryanto (1994) menjelaskan pada periode Kapur Awal terjadi aktivitas tektonik yang menyebabkan tersesarkannya batuan ultramafik dan malihan ke atas Kelompok Alino. Kemudia pada periode Paleosen tektonik menyebabkan batuan berumur Mesozoikum terangkat yang diikuti juga oleh batuan andesit porfiri. Aktivitas tektonik yang terakhir terjadi pada periode Miosen dan menyebabkan batuan tua terangkat. Batuan ini membentuk Tinggian Meratus dan memberikan tekanan pada batuan Tersier dan PreTersier sehingga terlipatkan. Bersamaan dengan aktivitas tektonik tersebut terjadi juga sesar naik, normal dan mendatar serta pembentukan Formasi Dahor pada Kala Pliosen. Persebaran formasi geologi regional dapat dilihat pada Gambar 2. 


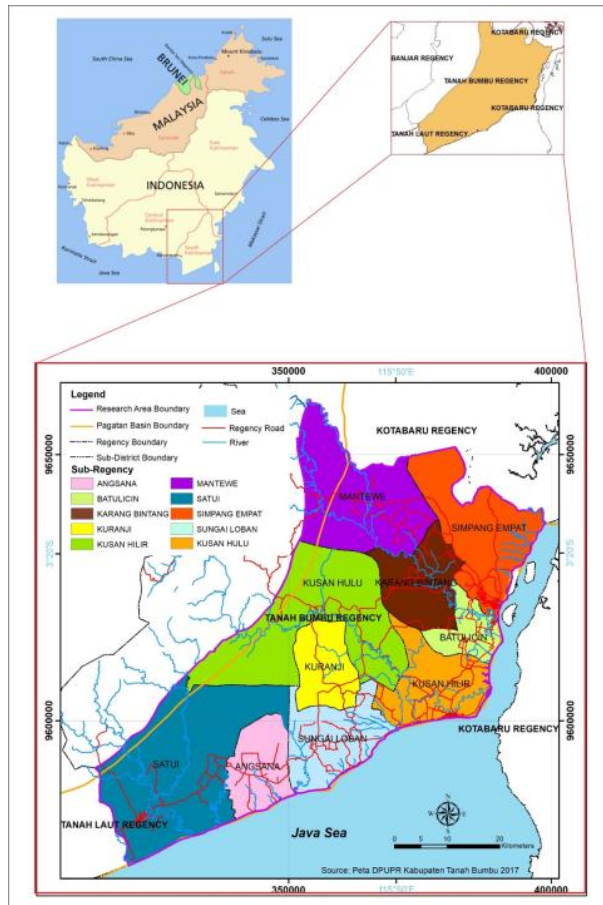

Gambar 1. Peta Lokasi Penelitian Cekungan Airtanah Pagatan

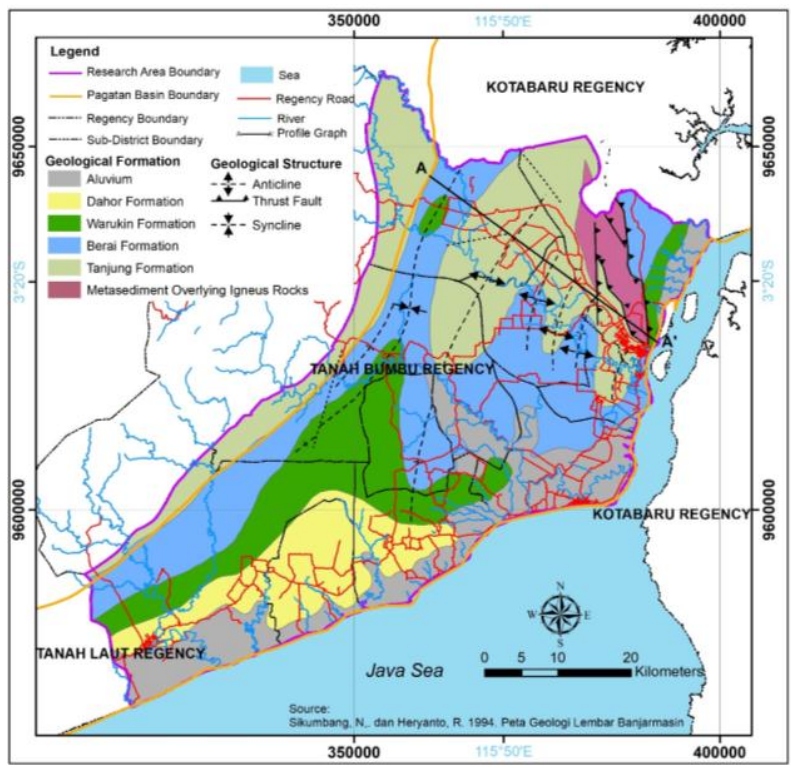

Gambar 2. Peta Geologi Regional

Menurut Sihwanto dan Wahyudin (2005), CAT Pagatan termasuk kedalam zona aman potensi kecil pada akuifer kedalaman $>30 \mathrm{mbmt}$. Pengambilan airtanah dibatasi maksimal $540 \mathrm{~m}^{3} /$ hari/sumur. Airtanah pada akuifer kedalaman $<30 \mathrm{mbmt}$ hanya untuk keperluan rumah tangga dengan debit pengambilan maksimal $100 \mathrm{~m}^{3} / \mathrm{bulan} /$ sumur. Karakteristik hidrogeologi yang penting pada daerah ini adalah potensi airtanah yang 
berada pada daerah penyelidikan semakin meninggi kearah tepi dari daerah penyelidikan. Terdapat 2 jenis akuifer di daerah penyelidikan, sebagai berikut (Gambar 3):

1. Mandala airtanah daratan, yaitu kenampakan morfologi pada daerah pantai, bantaran banjir (flood plain), serta dataran antara perbukitan atau pegunungan. Memiliki batuan penyusun lepas berukuran lempung, pasir dan kerikil sehingga aliran airtanah melewati sistem akuifer ruang antar butir.

2. Mandala airtanah karst, yaitu kenampakan khas morfologi pebukitan batugamping yang dicirikan oleh adanya celah, rekahan, dan saluran pelarutan sebagai media berlangsungnya aliran airtanah. Produktivitas akuifer di daerah ini tergantung pada tingkat karstifikasinya

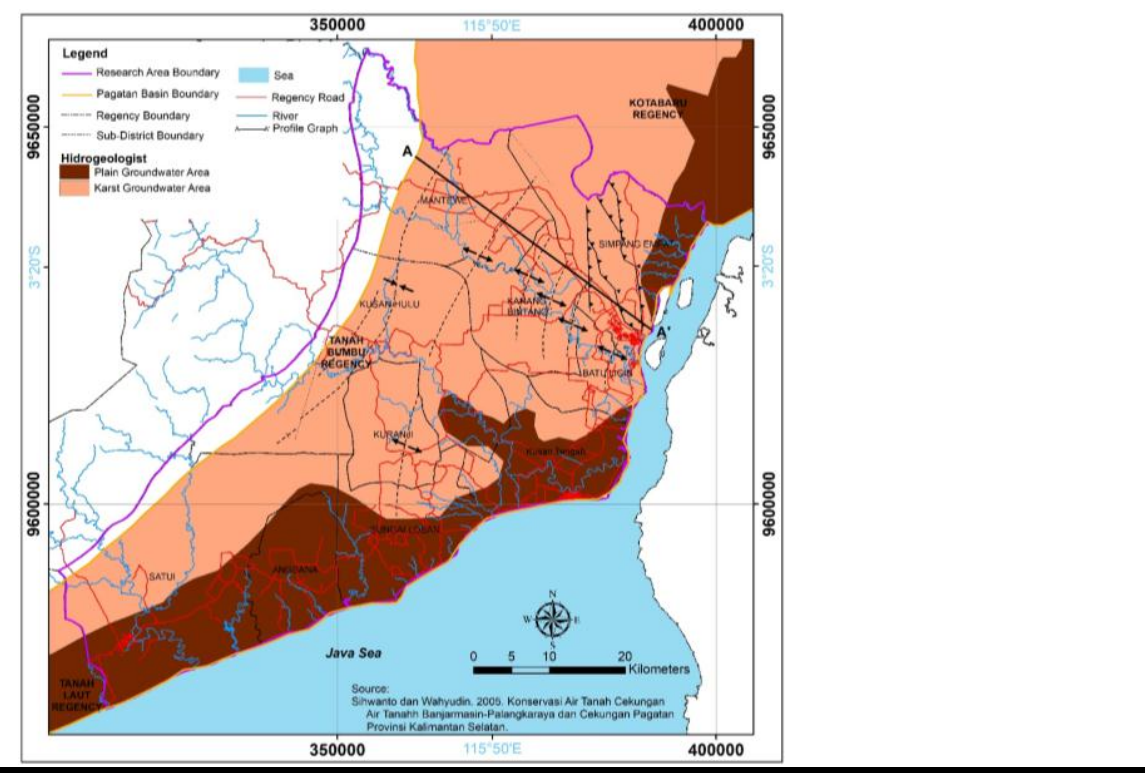

Gambar 3. Peta Hidrogeologi Regional

Berdasarakan profil sayatan didapatkan hasil bahwa pada daerah baratlaut dari Kecamatan Mentewe memiliki morfologi tinggian yang semakin lama semakin menurun yang jika ditarik batas, daerah ini merupakan daerah imbuhan dari airtanah (Gambar 4). Daerah ini dapat diindikasikan sebagai tipe batas H4. Semakin menuju arah tenggara dari profil sayatan yang berada di Kecamatan Karang Bintang merupakan batas dari H5, dimana merupakan batas cekungan airtanah dengan arah aliran airtanah menuju ke luar cekungan airtanah tersebut. Batas H5 berada di sekitar daerah pemukiman. Semakin menuju arah tenggara terdapat batas $\mathrm{H} 2$ yang berada pada daerah yang memiliki morfologi terjal. Dilihat dari kenampakan morfologinya, daerah ini memisahkan 2 aliran airtanah dengan arah yang berlawanan. Semakin menuju arah tenggara diantara Kecamatan Karang Bintang dan Kecamatan Simpang Empat terdapat daerah rendahan yang menjadi batas keluarnya airtanah atau merupakan tepi batas H5. Pada arah tenggara Kecamatan Simpang empat terdapat tinggian yang memisahkan 2 arah aliran airtanah dengan arah berlawanan (H2). Pada bagian tenggara sayatan pada Kecamatan Simpang Empat merupakan daerah pantai. Daerah ini merupakan batas paling rendah dari airtanah dan airtanah bersifat tetap sehingga merupakan tipe batas H3. 


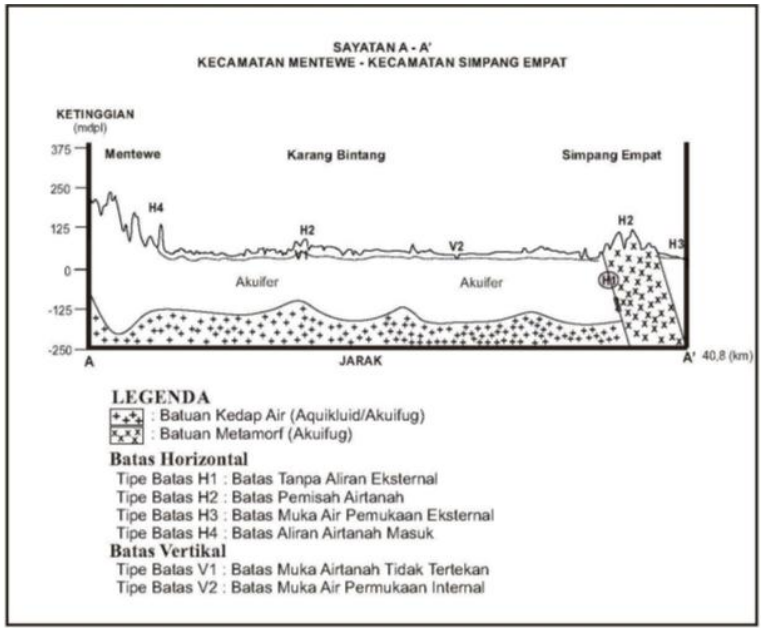

Gambar 4. Kondisi Hidrogeologi Daerah Penelitian

\section{Kualitas Airtanah}

Standar baku kualitas airtanah merupakan parameter yang digunakan untuk menentukan kualitas airtanah dalam hal untuk penyediaan air minum. Indonesia telah memiliki standar baku air minum yang layak minum telah ditentukan dalam Permenkes No.492/MENKES/PER/IV/2010 (Tabel 1).

Tabel 1. Standar Kualitas Air Minum

\begin{tabular}{|c|c|c|c|}
\hline & Parameter & $\begin{array}{c}\text { Maksimum Diperbolehkan } \\
\text { No.492/MENKES/PER/IV/2010 }\end{array}$ & Satuan \\
\hline \multicolumn{4}{|c|}{ 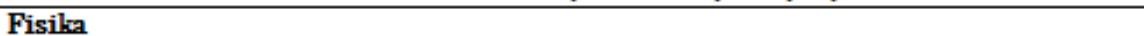 } \\
\hline 1. & Warna & 15 & Skala TCU \\
\hline 2. & Rasa & Tidak Berasa & - \\
\hline 3. & $\mathrm{Bau}$ & Tidak Berbau & - \\
\hline 4. & Daya Hantar Listrik & - & $\mu \mathrm{s} / \mathrm{cm}$ \\
\hline 5. & Kekeruhan & 5 & Skala NTU \\
\hline 6. & Zat Padat Terlarut (TDS) & 500 & $\mathrm{mg} / \mathrm{L}$ \\
\hline \multicolumn{4}{|c|}{ Kimia } \\
\hline 1. & $\mathrm{pH}$ & $6,5-8,5$ & unit $\mathrm{pH}$ \\
\hline 2 . & $\mathrm{Kalsium}\left(\mathrm{Ca}^{\mathrm{s}+}\right)$ & - & $\mathrm{mg} / \mathrm{L}$ \\
\hline 3. & Magnesium $\left(\mathrm{Mg}^{\mathrm{s}}\right)$ & - & $\mathrm{mg} / \mathrm{L}$ \\
\hline 4. & Besi $\left(\mathrm{Fe}^{2+}\right)$ & 0,3 & $\mathrm{mg} / \mathrm{L}$ \\
\hline 5. & Mangan $\left(\mathrm{Mn}^{\mathrm{s}+}\right)$ & 0,4 & $\mathrm{mg} / \mathrm{L}$ \\
\hline 6. & Kalium $\left(\mathrm{K}^{+}\right)$ & - & $\mathrm{mg} / \mathrm{L}$ \\
\hline 7 . & Natrium $\left(\mathrm{Na}^{+}\right)$ & - & $\mathrm{mg} / \mathrm{L}$ \\
\hline 8. & Litium $\left(\mathrm{Li}^{+}\right)$ & - & $\mathrm{mg} / \mathrm{L}$ \\
\hline 9. & Amonium $\left(\mathrm{NH}_{4}{ }^{+}\right)$ & 1,5 & $\mathrm{mg} / \mathrm{L}$ \\
\hline 10 & Karbonat $\left(\mathrm{CO}_{2}^{-}\right)$ & - & $\mathrm{mg} / \mathrm{L}$ \\
\hline 11. & Bikarbonat $\left(\mathrm{HCO}^{-}\right)$ & - & $\mathrm{mg} / \mathrm{L}$ \\
\hline 12. & Klorida $\left(\mathrm{Cl}^{-}\right)$ & 250 & $\mathrm{mg} / \mathrm{L}$ \\
\hline 13. & Sulfat $\left(\mathrm{SO}_{4}{ }^{2}\right)$ & 250 & $\mathrm{mg} / \mathrm{L}$ \\
\hline 14. & Nitrit $\left(\mathrm{NO}^{-}\right)$ & 3 & $\mathrm{mg} / \mathrm{L}$ \\
\hline 15. & Nitrat $\left(\mathrm{NO}_{-}^{-}\right)$ & 50 & $\mathrm{mg} / \mathrm{L}$ \\
\hline 16. & Kesadahan & 500 & $\mathrm{mg} / \mathrm{LCaCO}$, \\
\hline
\end{tabular}

Selain itu juga perlu dilakukan analisis Daya Hantar Listrik (DHL). DHL adalah kemampuan airtanah mengalirkan arus listrik dengan satuan mikrosiemen per sentimeter $(\mu \mathrm{S} / \mathrm{cm})$. Semakin tinggi daya hantar listrik menandakan semakin banyak kandungan unsur kimia yang terdapat pada airtanah. Peningkatan nilai DHL juga dapat diakibatkan oleh banyaknya polutan pada airtanah, (Scott dan Shah, 2004). 


\section{Tingkat Kerusakan dan Kondisi Airtanah}

Konservasi airtanah adalah upaya melindungi dan memelihara keberadaan, kondisi, dan lingkungan airtanah guna mempertahankan kelestarian dan atau kesinambungan ketersediaan dalam kuantitas dan kualitas dari airtanah (Danaryanto dkk., 2007). Airtanah adalah salah satu sumber air yang karena kualitas dan kuantitasnya cukup potensial untuk dikembangkan guna memenuhi kebutuhan dasar mahluk hidup, untuk itu harus adanya upaya melindungi dan memelihara demi kelangsungan makhluk hidup (Putranto dan Kusuma, 2009).

Keseimbangan antara jumlah ketersediaan airtanah dan penggunaannya merupakan faktor utama dalam menentukan tingkat kerusakan kondisi dan lingkungan airtanah (Danaryanto dkk., 2007). Faktor utama yang sangat menentukan tingkat kerusakan kondisi dan lingkungan airtanah dari keempat hal dasar di atas adalah penurunan muka airtanah dan penurunan kualitasnya.

1. Berdasarkan penurunan muka airtanah, tingkat kerusakan airtanah dapat dibagi menjadi 4 (empat) tingkatan sebagai berikut.

Aman : penurunan muka airtanah $<40 \%$

Rawan : penurunan muka airtanah $40-60 \%$

Kritis : penurunan muka airtanah $60-80 \%$

Rusak : penurunan muka airtanah $>80 \%$

2. Berdasarkan kualitas airtanah, tingkat kerusakan airtanah tertekan maupun tidak tertekan dapat dibagi menjadi 4 (empat) yaitu:

Aman : TDS (Total Dissolved Solid) menjadi $<1.000 \mathrm{mg} / \mathrm{L}$ atau DHL (Daya Hantar Listrik) $<1.000 \mu \mathrm{S} / \mathrm{cm}$.

Rawan : TDS menjadi $1.00010 .000 \mathrm{mg} / \mathrm{L}$ atau DHL menjadi $1.000-1.500 \mu \mathrm{S} / \mathrm{cm}$.

Kritis : TDS menjadi antara 10.000-100.000 mg/L atau nilai DHL 1.500-5.000 $\mu \mathrm{S} / \mathrm{cm}$.

Rusak : TDS menjadi $<100.000 \mathrm{mg} / \mathrm{L}$ atau tercemar oleh logam berat, dan atau bahan berbahaya dan beracun atau DHL $>5.000 \mu \mathrm{S} / \mathrm{cm}$.

Menurut Danaryanto dkk. (2007), tingkat kerusakan kondisi dan lingkungan airtanah mengacu pada pertimbangan ada tidaknya amblesan tanah, sehingga pembuatan zonanya dibagi menjadi dua sebagai berikut :

Aman : Apabila pengambilan airtanah belum menyebabkan terjadinya amblesan tanah.

Rusak : Apabila pengambilan airtanah telah menyebabkan terjadinya amblesan tanah.

Berdasarkan pertimbangan penurunan muka airtanah dan kualitasnya, serta ada tidaknya amblesan tanah tersebut, maka tingkat kerusakan kondisi dan lingkungan airtanah dapat ditentukan berdasarkan matriks seperti pada Tabel 2, sebagai berikut :

\section{METODE}

Penelitian hidrogeologi pada Kabupaten Tanah Bumbu menggunakan dua metode, yaitu metode observasi dan metode analisis. Pada metode observasi, dilakukan pemetaan kondisi geologi permukaan, pengukuran muka airtanah (MAT) pada akuifer bebas, dan pengambilan sampel sumur gali pada daerah penelitian.. Hasil penelitian dengan kedua metode tersebut berupa zona konservasi dan pemanfaatan airtanah pada akuifer bebas di wilayah CAT Pagatan.

Pengukuran kedalaman muka airtanah (mbmt) dilakukan pada 150 titik sumur gali. Data kedalaman MAT, kedalaman sumur, elevasi dan koordinat. Data kedalaman MAT dan kedalaman sumur kemudian dikonversi menjadi data kedudukan dengan selisih antara elevasi dan nilai tersebut, sehingga didapatkan kedudukan MAT dan kedudukan dasar 
sumur dalam mdpl. Data kedudukan MAT digunakan dalam pembuatan model pola dan aliran airtanah akuifer bebas dengan metode gridding minimum curvature menggunakan bantuan software Surfer 11, kemudian dilakukan layout peta dengan bantuan software ArcGIS 10.3.

Tabel 2. Standar Kualitas Air Minum

\begin{tabular}{|c|c|c|c|c|c|}
\hline Kualitas & $<40 \%$ & $40 \%-60 \%$ & $60 \%-80 \%$ & $>80 \%$ & $\begin{array}{c}\text { Amblesan } \\
\text { Tanah }\end{array}$ \\
\hline $\begin{array}{l}\text { TDS }<1.000 \mathrm{mg} / \mathrm{L} \\
\text { DHL }<1.000 \mu \mathrm{s} / \mathrm{cm}\end{array}$ & Aman & & \multirow[b]{3}{*}{ Kritis } & \multirow[b]{4}{*}{ Rusak } & \multirow{3}{*}{ Kritis } \\
\hline $\begin{array}{l}\text { TDS } 1.000-10.000 \mathrm{mg} / \mathrm{L} \\
\text { DHL } 1.000-1.500 \mu \mathrm{S} / \mathrm{cm}\end{array}$ & & Rawan & & & \\
\hline $\begin{array}{l}\text { TDS } 10.000-100.000 \mathrm{mg} / \mathrm{L} \\
\text { DHL } 1.500-5.000 \mu \mathrm{S} / \mathrm{cm}\end{array}$ & & & & & \\
\hline $\begin{array}{l}\text { TDS }>100.000 \mathrm{mg} / \mathrm{L} \\
\text { DHL }>5.000 \mu \mathrm{S} / \mathrm{cm} \\
\text { Logam berat dan B3 }\end{array}$ & & & & & \\
\hline
\end{tabular}

Identifikasi kualitas airtanah berdasarkan 2 parameter, yaitu sifat fisik dan kimia airtanah. Identifikasi kualitas airtanah berdasarkan sifat fisik menggunakan parameter rasa, bau, dan warna yang disesuaikan dengan parameter standar kualitas air minum berdasarkan Permenkes No.492 Tahun 2010. Identifikasi kualitas airtanah berdasarkan sifat kimia airtanah terdiri dari 4 aspek yaitu: pH, DHL, kesadahan, dan kandungan ion terlarut. Pembuatan peta analisa ini berdasarkan hasil pengukuran $\mathrm{pH}$ dari sampel airtanah menggunakan alat WTW pH 3210 SET 2 dan pengukuran dan DHL dari sampel airtanah menggunakan alat WTW Cond 3310 SET 1. Data $\mathrm{pH}$ dan DHL yang telah didapat kemudian digunakan dalam pembuatan model pola persebaran $\mathrm{pH}$ dan DHL dengan metode gridding minimum curvature menggunakan bantuan software Surfer 11, kemudian dilakukan layout peta dengan bantuan software ArcGIS 10.3. Kandungan ion terlarut yang dilakukan uji laboratorium adalah ion $\left(\mathrm{Ca}^{2+}\right),\left(\mathrm{Mg}^{2+}\right),\left(\mathrm{Fe}^{3+}\right),\left(\mathrm{Mn}^{2+}\right),\left(\mathrm{K}^{+}\right),\left(\mathrm{Na}^{+}\right),\left(\mathrm{Li}^{+}\right)$, $\left(\mathrm{NH}_{4}{ }^{+}\right),\left(\mathrm{CO}_{3}^{-}\right),\left(\mathrm{HCO}_{3}^{-}\right),\left(\mathrm{Cl}^{-}\right),\left(\mathrm{SO}_{4}{ }^{2}\right)$, $\left(\mathrm{NO}^{2}\right)$, dan $\left(\mathrm{NO}_{3}^{-}\right)$.

Pembuatan peta zona konservasi airtanah mengacu pada penentuan matriks penentuan peringkat kerusakan kondisi dan lingkungan airtanah (Danaryanto dkk., 2007). Selain menggunakan matriks penentuan peringkat kerusakan kondisi dan lingkungan airtanah, penyusunan peta zona konservasi airtanah juga di sesuaikan dengan parameter, yaitu nilai $\mathrm{pH}$, dan arah aliran MAT. Pembuatan peta zona pemanfaatan dan perlindungan airtanah menggunakan bantuan software ArcGIS 10.3

\section{HASIL DAN PEMBAHASAN}

\section{Pola Aliran Airtanah Bebas}

Sistem airtanah pada CAT Pagatan di Kabupaten Tanah Bumbu diambil 150 sampel sumur gali dengan dilakukan pengukuran muka airtanah pada setiap sampel sumur gali. Inventarisasi titik minatan sumur gali yang terdiri dari 150 titik minatan ditunjukkan pada Gambar 5. Titik minatan menjadi dasar pembuatan arah aliran muka airtanah seperti pada Gambar 6. Berdasarkan pengukuran muka airtanah pada sumur gali, didapat hasil bahwa pada daerah penelitian memiliki kedalaman antara 0,7 mdpl yang berada di Kecamatan Batulicin Putih hingga kedalaman 49,2 mdpl yang terdapat di Kecamatan Mentewe. Berdasarkan hasil penelitian menunjukkan bahwa kecenderungan pola aliran airtanah cenderung menyebar ke arah timur menuju daerah Kecamatan Karang Bintang, menuju 
Kecamatan Sungai Loban, dan pada Kecamatan Satui cenderung mengalir ke arah selatan seperti pada gambar 6 .

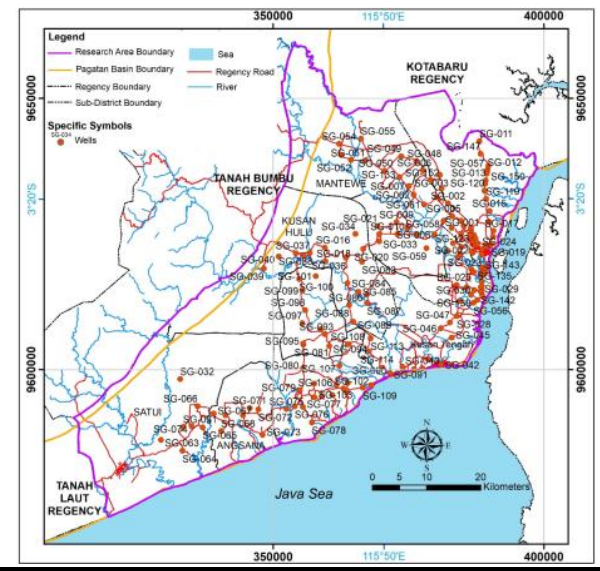

Gambar 5. Peta Inventarisasi Titik Minatan Sumur Gali

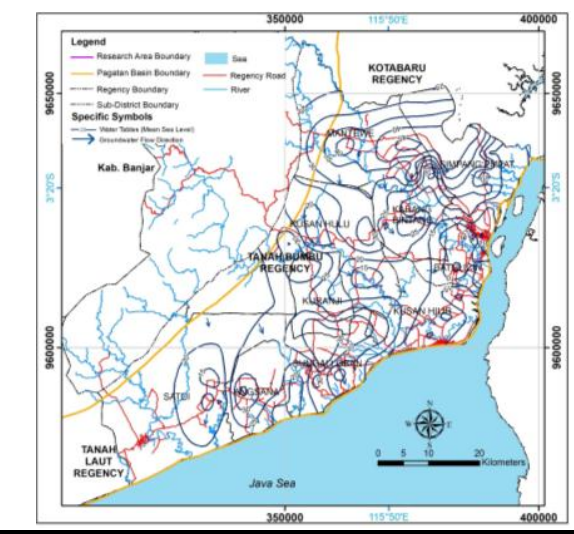

Gambar 6. Peta Arah Aliran Muka Airtanah

\section{Sifat Fisika Airtanah}

Bedasarkan analisis uji laboratorium dari data yang didapatkan dilapangan, kualitas airtanah layak minum adalah yang memiliki sifat fisik tidak berwarna, tidak berbau, tidak berasa, dan tidak keruh. Daerah penelitian terdapat sampel airtanah yang memiliki warna, rasa, dan kekeruhan yang tidak sesuai dengan kualitas air layak minum. Daerah penelitian ini juga terdapat sampel airtanah yang memiliki kualitas airtanah yang tidak memenuhi kriteria air minum yang layak untuk diminum menurut peraturan menteri kesehatan No.492 Tahun 2010 (PERMENKES NO.492/MENKES/PER/IV/2010). Berdasarkan data lapangan pada sumur gali didapat 3 jenis karakteristik airtanah, yaitu;

a. Beberapa contoh air dengan warna keputihan dengan sifat keruh, rasanya asam dan tidak berbau berada di lokasi Sumur SG-30 yang terletak di Desa Batulicin Kecamatan Batulicin dan SG-074 yang terletak di Desa Wonorejo Kecamatan Satui, termasuk ke dalam kategori air layak minum

b. Terdapat juga beberapa contoh air dengan sifat sangat keruh, warna kuning kecoklatan seperti pada lokasi Sumur SG-073 yang terletak di Desa Mekar Jaya Kecamatan Angsana dan Sumur SG-078 yang terletak di Desa Dwimarga Kecamatan Sungai Loban, termasuk ke dalam kategori air tidak layak minum 
c. Contoh air dengan warna air putih mendekati bening, sedikit keruh dan asam seperti pada sumur SG-070 yang berada di Desa Bayan Sari Kecamatan Angsana. Berdasarkan ciri sifat fisik seperti warna, rasa dan kekeruhan, sumur gali yang memiliki rasa asam tidak termasuk ke dalam kategori air layak minum

Berdasarkan analisis penyebab berubahnya warna dan kekeruhan airtanah menjadi keruh dan kekuningan dapat disebabkan karena batuan yang berada di sekitar sumur gali. Batuan yang berada pada sekitar sumur belum mengalami kompaksi dengan sempurna seperti pada litologi Aluvium sehingga material lepasan dapat bercampur pada airtanah sehingga airtanah bersifat keruh. Batupasir pada Formasi Dahor dan Warukin juga dapat menjadi salah satu penyebab keruhnya air sumur, hal itu dikarenakan sifat dari batupasir pada formasi tersebut yang mudah hancur. Penyebab berubahnya warna airtanah menjadi putih dan keruh dapat disebabkan karena kandungan karbonat pada Formasi Berai. Batuan penyusun pada Formasi Berai berupa batugamping, dimana batuan tersebut dapat mengalami pelarutan karbonat dan terlarut ke dalam akuifer pada airtanah yang tidak dapat menyaring kandungan karbonat sehingga airtanah berwarna putih.

Berubahnya rasa airtanah pada sumur gali dapat disebabkan oleh keadaan litologi pada daerah sekitar. Keberadaan airtanah terdapat pada batupasir Formasi Dahor dan Formasi Warukin yang berdasarkan geologi regional memiliki kandungan konkresi besi. Konkresi besi dapat diindikasikan menjadi penyebab dari berubahnya rasa airtanah. Satuan Aluvium juga dapat mempengaruhi perubahan rasa airtanah pada air sumur gali, dimana saat proses pengendapan material lempung-pasir juga membawa material organik (tumbuhan). Endapan material organik yang ikut terendapkan bersamaan dengan material lempung-pasir pada satuan Aluvium mengalami pembusukan sehingga merubah cita rasa dari airtanah.

\section{Sifat Kimia Airtanah}

Identifikasi kualitas airtanah berdasarkan sifat kimia airtanah terdiri dari 4 aspek yaitu: $\mathrm{pH}$, DHL, kesadahan, dan kandungan ion terlarut.

1. Derajat Keasaman $(\mathrm{pH})$

Berdasarkan hasil analisis uji laboratorium dari 150 sampel sumur gali, terdapat 103 sampel sumur yang memiliki $\mathrm{pH}$ dibawah 6,5. Persebaran nilai $\mathrm{pH}$ berkisar antara nilai 2,87 yang berada di SG-128 di Desa Kuranji Kecamatan kuranji hingga nilai 7,8 di SG-17 yang berada di Desa Gunung Besar Kecamatan Simpang Empat. Berdasarkan PERMENKES NO.492/MENKES/PER/IV/2010, terdapat 103 sampel yang tidak memenuhi standar sebagai bahan baku air minum karena memiliki nilai $\mathrm{pH}$ di bawah 6,5. Pada daerah penelitian tidak ditemukan sampel yang memiliki nilai $\mathrm{pH}$ lebih dari 8,5.

Sampel sumur gali yang memiliki $\mathrm{pH}$ dibawah 6,5 terdapat pada batupasir pada Formasi Dahor, satuan Aluvium, dan batugamping pada Formasi Berai. Penyebab dari menurunnya $\mathrm{pH}$ hingga mencapai nilai 2,87 tersebut dapat diindikasikan karena pengaruh dari penggunaan lahan yang didominasi oleh kawasan perkebunan. Perkebunan yang paling mendominasi pada daerah penelitian adalah kebun sawit dan kebun karet. Penggunaan pupuk yang tidak tepat dapat menyebabkan berubahnya sifat kimia airtanah termasuk $\mathrm{pH}$ airtanah pada daerah penelitian. Pola persebaran $\mathrm{pH}$ dapat dilihat pada Gambar 7.

2. Daya Hantar Listrik (DHL)

Semakin tinggi nilai DHL pada umumnya akan mempengaruhi kualitas dari airtanah (Wilcox dan Breshears., 1995). Peningkatan nilai DHL juga dapat diakibatkan oleh banyaknya polutan pada airtanah, (Badiani dan Jessoe, 2012). Klasifikasi nilai DHL dapat dilihat pada Tabel 3 (Wilcox, 1955 dalam Zekai, 2015). 


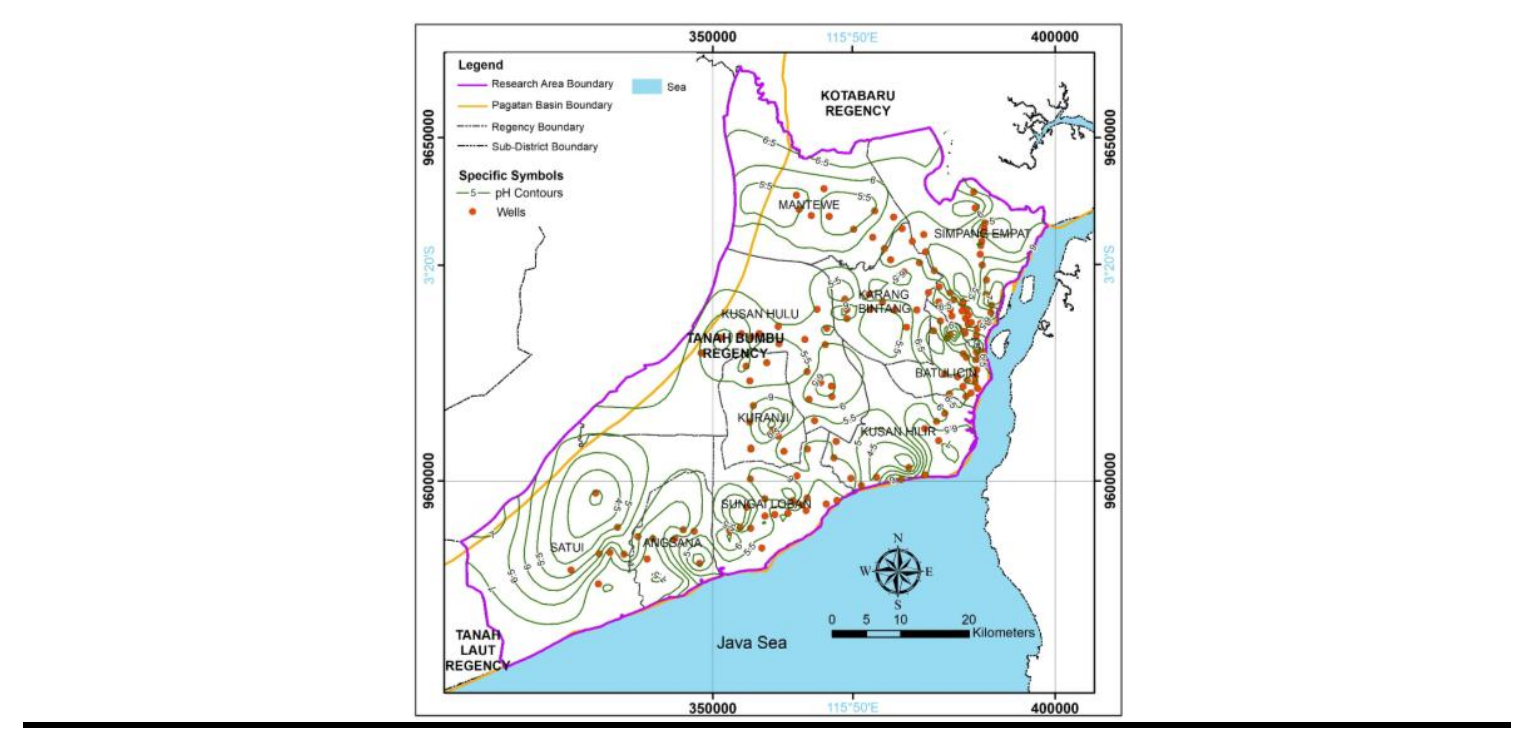

Gambar 7. Peta Persebaran Ph

Table 3. Klasifikasi air berdasarkan daya hantar listrik (Wilcox, 1955 dalam Zakai, 2015).

\begin{tabular}{ll}
\hline Daya hantar listrik $(\mu \mathrm{S} / \mathrm{cm})$ & Kualitas Air \\
\hline$<250$ & Sangat Baik \\
$250-750$ & Baik \\
$750-2.000$ & Sedang \\
$2.000-3.000$ & Buruk \\
$\geq 3.000$ & Sangat Buruk \\
\hline
\end{tabular}

Berdasarkan hasil pengukuran nilai DHL yang berjumlah 150 titik sampel sumur gali, memiliki nilai DHL berkisar antara adalah $14,9 \mu \mathrm{S} / \mathrm{cm}$ yang terletak pada sumur SG143 di Desa Batulicin Kecamatan Batulicin hingga nilai $1.477 \mu \mathrm{S} / \mathrm{cm}$ yang terletak pada sumur SG-44 di Desa Baru Gelang Kecamatan Kusan Hilir. Tingginya nilai DHL menandakan kandungan unsur kimia dan kandungan polutan yang tinggi. Nilai DHL yang tinggi dapat diakibatkan karena kondisi geologi sekitar. Kandungan material dari satuan Aluvium yang belum mengalami kompaksi dengan baik menyebabkan material pada Alluvium tidak dapat tersaring dan bercampur pada airtanah.

Berdasarkan klasifikasi kualitas airtanah (Tabel 3), terdapat 4 sampel airtanah yang memiliki nilai DHL 750 hingga 1.477. Kualitas airtanah dengan nilai DHL di atas 750-2.000 $\mu \mathrm{S} / \mathrm{cm}$ termasuk dalam kategori sedang. Nilai DHL yang melebihi $750 \mu \mathrm{S} / \mathrm{cm}$ terdapat pada sampel SG-068 yang berada di Desa Sumber Baru pada Kecamatan Angsana, sampel SG-144 yang berada di Desa Batulicin pada Kecamatan Batulicin, sampel SG-128 yang berada di Desa Kuranji pada Kecamatan Kuranji, dan sampel SG-044 yang berada di Desa Baru Gelang di Kecamatan Kusan Hilir. Pola Persebaran DHL dapat dilihat pada Gambar 8. 3. Kesadahan

Kesadahan dapat di sebabkan karena mengendapnya unsur kalsium dan kalium dalam airtanah. Penyebab kesadahan airtanah paling besar di daerah penelitian adalah batugamping pada Formasi Berai. Batas toleransi kesadahan untuk keperluan air minum berdasarkan ketentuan dari Peraturan Menteri Kesehatan No.492 Tahun 2010 adalah 500 $\mathrm{mg} / \mathrm{L}$. Berdasarkan hasil analisis laboratorium, meskipun terdapat Batugamping pada Formasi Berai, namun tidak ditemukan kandungan kesadahan yang melebihi kadar maksimum dari Peraturan Menteri Kesehatan No.492 Tahun 2010. Berdasarkan hasil tersebut, jika ditinjau dari nilai kesadahan pada sumur gali layak digunakan sebagai air minum meskipun harus ditinjau dari beberapa aspek lainnya. 


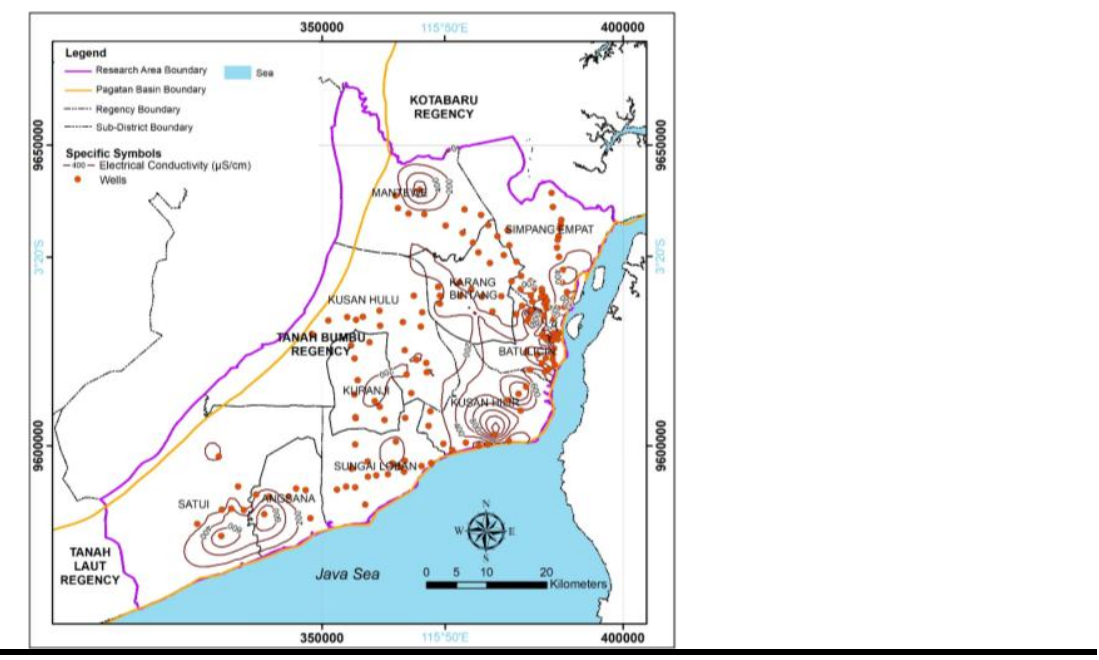

Gambar 8. Peta Persebaran DHL

4. Kandungan Ion Terlarut

Kandungan ion yang terdapat dalam seluruh contoh air adalah kalsium (Ca2+), magnesium $(\mathrm{Mg} 2+)$, besi $((\mathrm{Fe} 3+)$, mangan $(\mathrm{Mn} 2+)$, kalium $(\mathrm{K}+)$, natrium $(\mathrm{Na}+)$, litium $(\mathrm{Li}+)$, amonium (NH4+), karbonat (CO3-), bikarbonat (HCO3-), klorida (Cl-), sulfat (SO42), nitrit (NO2), dan nitrat (NO3-). Berdasarkan hasil analisis, terdapat 9 sampel yang memiliki kandungan ion melebihi batas PERMENKES NO. 492/MENKES/PER/IV/2010, yaitu pada sampel SG-070, SG-73, SG-30, SG-78, SG-38, SG-86, SG-113, dan SG-114.

\section{Pemanfaatan Airtanah}

Berdasarkan data DPUPR Kabupaten Tanah Bumbu Tahun 2017, penggunakan lahan pada lokasi penelitian di dominasi oleh kawasan perkebunan, kawasan hutan industri, dan sebagian lokasi pemukiman warga. Masyarakat memanfaatkan airtanah sumur gali untuk keperluan domestik seperti irigasi, keperluan rumah tangga seperti mandi, cuci, dan air minum. Pada Kecamatan Satui, Angsana, Sungai Loban, dan Kusan Hilir sebagian besar wilayahnya dimanfaatkan oleh PDAM setempat untuk pemenuhan kebutuhan air bersih kepada masyarakat setempat (Gambar 9).

\section{Zona Konservasi Airtanah}

Berdasarkan tidak adanya data sekunder berupa kedalaman muka airtanah akuifer bebas pada daerah penelitian, penentuan identifikasi zona konservasi airtanah pada akuifer bebas dilakukan berdasarkan nilai DHL serta hal penting lainnya yang berkaitan. Berdasarkan hasil penelitian didapat 2 hasil yang terbagi atas daerah imbuhan airtanah, dan daerah pemanfaatan airtanah yang terbagi menjadi 2 (dua) zona, yaitu zona aman dan zona rawan (Gambar 10). Berdasarkan hasil tersebut dapat dijelaskan sebagai berikut:

1. Daerah Imbuhan

Secara umum, daerah imbuhan airtanah berada di wilayah bagian barat dari Kecamatan Mentewe, Kecamatan Kusan Hulu, dan Kecamatan Satui. Daerah ini didominasi oleh litologi mudah lolos air atau tidak jenuh air, seperti batupasir dan batugamping. Nilai DHL pada zona ini antara $34 \mu \mathrm{S} / \mathrm{cm}$ hingga $415 \mu \mathrm{S} / \mathrm{cm}$. Daerah ini memiliki kedalaman MAT 7,2 mbmt hingga 7,5 mbmt. Nilai $\mathrm{pH}$ pada daerah ini cenderung normal yaitu antara 6-7, kecuali pada bagian utara Kecamatan Satui yang memiliki nilai pH 5. Penggunaan airtanah hanya diizinkan untuk pemenuhan kebutuhan domestik. Penggunaan airtanah akuifer bebas diperbolehkan setelah dilakukan kajian hidrogeologi detail. Pembuangan limbah masyarakat perlu diperhatikan agar tidak mencemari di daerah lepasan. Sebaiknya seluruh kawasan di zona ini dijadikan kawasan perlindungan. 


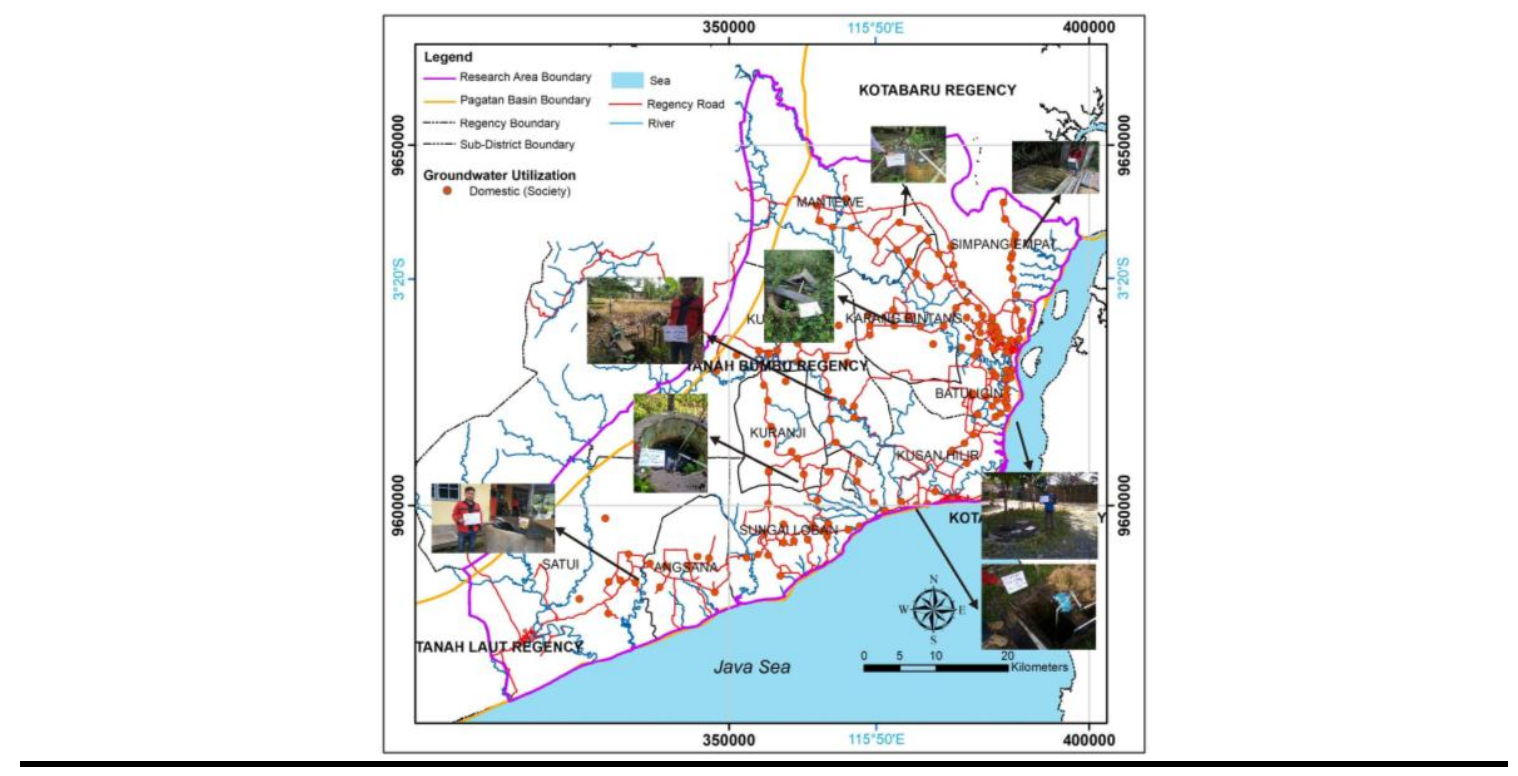

Gambar 9. Peta Pemanfaatan Airtanah

2. Zona Pemanfaatan Airtanah

CAT Pagatan di Kabupaten Tanah Bumbu berdasarkan zona pemanfaatan dibagi menjadi 2 sub zona yaitu zona aman dan zona rawan.

a. Sub Zona Aman

Zona ini berada pada wilayah Kecamatan Kecamatan Satui, Kecamatan Angsana, Kecamatan Sungai Loban, Kecamatan Kusan Hilir, Kecamatan Mentewe, Kecamatan Karang Bintang, Kecamatan Batulicin, Kecamatan Kusan Raya, Kecamatan Kuranji, Kecamatan Simpang Empat. Wilayah ini tersusun atas satuan Aluvium, Formasi Dahor, Formasi Warukin, dan Formasi Tanjung.

Berdasarkan hasil penelitan, yang bertindak sebagai akuifer utama adalah batupasir kuarsa sisipan kerikil sampai kerakal dari Formasi Dahor, batupasir kerikil, sisipan kerakal, sisipan lempung dari Formasi Warukin, dan Batugamping pada Formasi Tanjung. Nilai DHL pada zona ini antara 415-975 $\mu \mathrm{S} / \mathrm{cm}$. Berdasarkan hasil pengukuran kedalaman muka airtanah, daerah ini memiliki kedalaman 2,4-7,2 mbmt. Airtanah pada zona ini masih dimanfaatkan untuk kebutuhan pokok sehari-hari perorangan.

Zona ini perlu dilakukan upaya untuk menjaga agar airtanah tidak terdegradasi menjadi zona rawan. Hal-hal yang harus dilakukan adalah pembuangan air kotoran limbah domestik perlu dikelola terlebih dahulu, tidak ada pembuangan sampah akhir. Upaya lain adalah melakukan pengawasan penggunaan airtanah, menjaga pasokan air bersih dan mengendalikan jumlah pengambilan airtanah, membangun sumur pantau, dan pembuatan sumur imbuhan airtanah. 


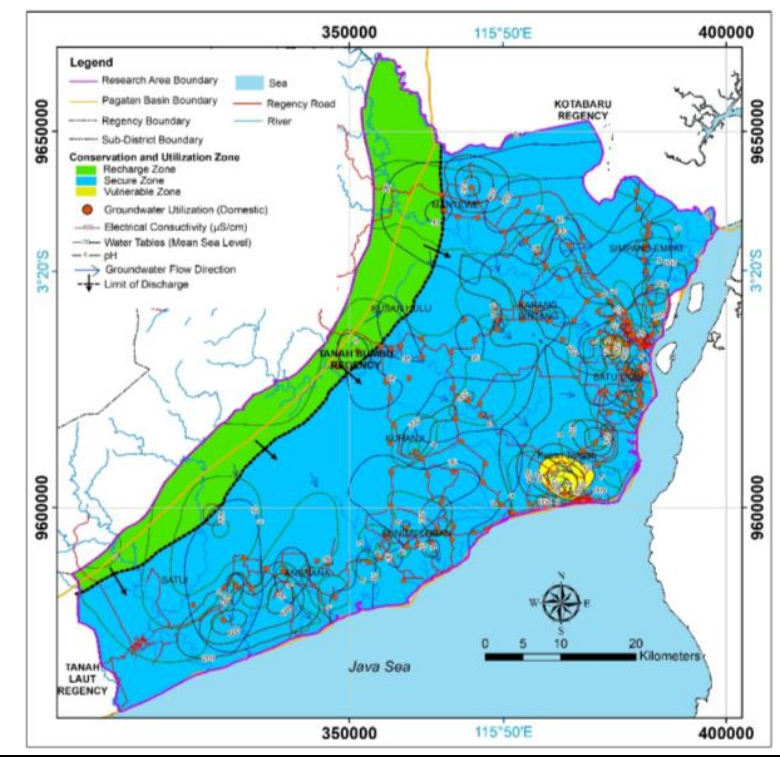

\section{Gambar 10. Peta Zona Konservasi dan Pemanfaatan Airtanah}

\section{b. Sub Zona Rawan}

Zona ini terdapat pada wilayah bagian Selatan pada Kecamatan Kusan Hilir, dan wilayah bagian utara pada Kecamatan Batulicin. Berdasarkan hasil penelitan, yang bertindak sebagai akuifer utama berupa material lempung dan lanau dari aluvium, batupasir dari Formasi Berai. Nilai DHL pada zona ini antara 1.050-1.477 $\mu \mathrm{S} / \mathrm{cm}$. Nilai pH pada zona ini antara 3-6. Pengambilan airtanah pada daerah ini dilakukan pada sumur gali dengan kedalaman MAT 0,2-2,4 mbmt. Airtanah pada daerah ini masih digunakan sebagai kebutuhan masyarakat (domestik). Masyarakat masih menggunakan sumur gali pada daerah ini dikarenakan belum terjangkau oleh pelayanan air bersih.

Zona ini sudah seharusnya mendapatkan pelayanan air bersih seperti PDAM karena jika ditinjau dari kandungan DHL atapun $\mathrm{pH}$, daerah ini tidak memenuhi standar kualitas air minum menurut peraturan menteri kesehatan No. 492 tahun 2010

\section{Kesesuaian Zona Konservasi dan Pemanfaatan Airtanah Terhadap Pengembangan Tata Ruang Wilayah}

Dari kajian di lapangan, karakter penggunaan lahan pada kawasan imbuhan airtanah CAT Pagatan di Kabupaten Tanah Bumbu yang terdapat di bagian selatan-barat merupakan daerah tinggian. Kawasan hutan lindung harus terletak pada zona imbuhan agar penyerapan air dapat maksimal, letak kawasan industri berada pada daerah lepasan airtanah, yang mana jarak masing-masing sumur gali atau sumur bor tidak diperbolehkan saling berdekatan sehingga kualitas dan kuantitas airtanah tetap terjaga. Daerah ini didominasi oleh perkebunan, hutan dan tegalan. Berdasarkan Peta Rencana Tata Ruang dan Wilayah Kabupaten Tanah Bumbu Tahun 2017-2037

Berdasarkan atas karakteristik penggunaaan lahannya, maka pada daerah imbuhan airtanah bagian barat dari Kecamatan Mentewe, Kecamatan Kusan Hulu, dan Kecamatan Satui didominasi oleh Kawasan Lindung dan Kawasan Hutan Produksi Tetap. Berdasarkan atas hal tersebut terlihat adanya kesesuaian antara kawasan imbuhan airtanah dengan pola tata ruang yang saling sinergi untuk menciptakan kelestarian ekosistem hidrologi daerah imbuhan airtanah tersebut. Selain itu terdapat langkah-langkah yang harus diambil untuk menjaga kondisi dan lingkungan airtanah agar tidak mengalami penurunan kualitas dan kuantitas airtanah di CAT Pagatan. Langkah-langkah perlu diambil adalah sebagai berikut: 
a. Melindungi kawasan di sekitar daerah imbuhan dengan cara melarang segala bentuk kegiatan budidaya yang dapat berisiko merubah kualitas dan kuantitas airtanah.

b. Membuat sumur pantau terutama di daerah yang pengambilan airtanahnya intensif seperti di kawasan pemukiman pada wilayah Kecamatan Karang Bintang dan Batulicin untuk mengetahui kondisi airtanah apabila terdapat perubahan kuantitas dan kualitas airtanah.

c. Memberikan pengetahuan kepada masyarakat tentang pelestarian dan pemanfaatan airtanah sehingga airtanah dapat digunakan secara maksimal.

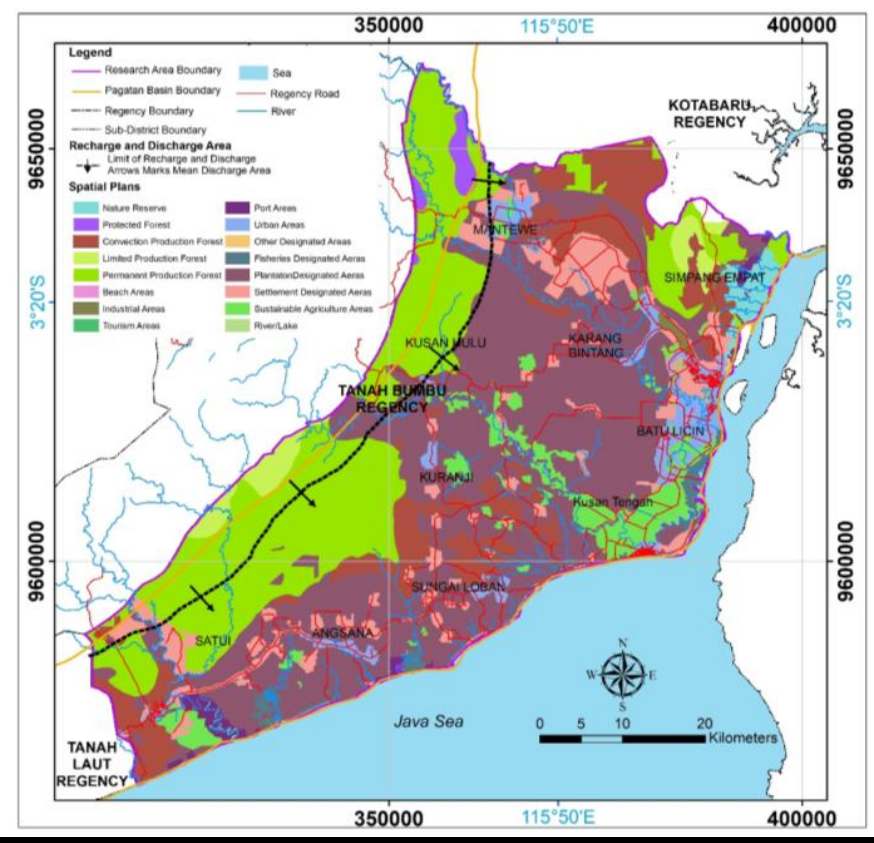

\section{Gambar 11. Peta Kesesuaian Zona Konservasi dan Pemanfaatan Airtanah Terhadap Pengembangan Tata Ruang Wilayah}

\section{KESIMPULAN}

Hasil analisis 150 sampel airtanah yang yang terdiri dari sampel sumur gali menunjukkan bahwa keseluruhan sampel memenuhi syarat untuk keperluan air minum kecuali pada kandungan $\mathrm{pH}$ sesuai dengan Peraturan Menteri Kesehatan Nomor. 429 Tahun 2010. Dari 150 sampel airtanah terdapat 9 sampel yang tidak memenuhi memenuhi syarat untuk keperluan air minum. Sampel airtanah yang tidak sesuai berada di tata guna lahan kawasan peruntuhan perkebunan. Berdasarkan peta RTRW, menurunnya kualitas airtanah di sebabkan karena penggunaan pupuk yang tidak tepat.

Berdasarkan atas kesamaan ketersediaan airtanah, kesamaan tingkat kerusakan airtanah dan kesamaan pengaturannya maka wilayah CAT Pagatan dibagi menjadi 3 zona, yaitu zona imbuhan, zona aman, dan zona rawan.

Kecamatan Satui, Angsana, Sungai Loban, dan Kusan Hilir sebagian besar wilayahnya dimanfaatkan oleh PDAM setempat untuk pemenuhan kebutuhan air bersih kepada masyarakat setempat. Berdasarkan Peta Rencana Tata Ruang dan Wilayah Daerah CAT Pagatan mengacu pada Peta Rencana Tata Ruang dan Wilayah Kabupaten Tanah Bumbu Tahun 2017-2037 kawasan imbuhan didominasi oleh Kawasan Lindung dan Kawasan Hutan Produksi Tetap. Berdasarkan atas hal tersebut terlihat adanya kesesuaian antara kawasan imbuhan airtanah dengan pola tata ruang wilayah. 
Berrdasarkan zona pemanfaatan dan konservasi airtanah cat pagatan diketahui bahwa daerah yang banyak memanfaatkan airtanah adalah wilayah kecamatan batulicin, kecamatan simpang empat, dan kecamatan karang bintang sehingga perlu adanya pemantauan terhadap penggunaan sumur gali di daerah tersebut.

\section{DAFTAR PUSTAKA}

Badan Pusat Statistik Kabupaten Tanah Bumbu. 2016. Kabupaten Tanah Bumbu dalam Angka. 2017. Peta Rencana Tata Ruang dan Wilayah Tahun 2017-2037.

Badan Perencanaan dan Pembangunan Daerah (BAPPEDA) Provinsi Kalimantan Selatan. 2017. Album Peta RTRW Provinsi Kalimantan Selatan. Banjarmasin.

Badiani, R., dan Jessoe, K. 2012. The Impact of Electricity Subsidies on Groundwater Extraction and Agriculture Production. Department of Agricultural Economics, University of California, Davis.

Chang, F, J., Huang, C, W., Cheng, S, T., dan Chang, L, C. 2017. Conservation Of Groundwater From OverExploitation-Scientific Analyses For Groundwater Resources Management. Science of the Total Environment, Volume 1: 828-838.

Danaryanto., Titomiharjo, H., Setiadi, H., dan Siagian, Y. 2007. Kumpulan Pedoman Teknis Pengelolaan Airtanah. Badan Geologi: Bandung.

Eulenstein, F., Tauschke, M., Schindler, U., Müller, L., Lana, M, A., Schindler, R., Maverc, W, H., Drechsler, H., dan Cremere, N. 2016. Agricultural Land Use Systems and Groundwater Quality: Impact Assessment Using Nutrient Balances for Evaluation, Monitoring and Conservation of Natural Resources. ICIISA, Volume 11: 49-58.

Lewis, D, B. 2016. Response of wetland soil carbon to groundwater conservation: Probabilistic outcomes from error propagation. Ecological Indicators, Volume 60: 538-547.

Peraturan Menteri ESDM No. 13 Tahun 2009. Pedoman Penyusunan Rancangan Penetapan Cekungan Air tanah.

Peraturan Menteri ESDM No. 2 Tahun 2017. Cekungan Air Tanah di Indonesia.

Peraturan Menteri Kesehatan No.492/MENKES/PER/IV/2010. 2010. Persyaratan Kualitas Air Minum.

Putranto, T, T., dan Kusuma, K, I. 2009. Permasalahan Airtanah Pada Daerah Urban. Teknik, Volume 30(1).

Rao, M, N., dan Yang, Z. 2010. Groundwater impacts due to conservation reserve program in Texas County, Oklahoma. Applied Geography, Volume 30: 317-328.

Satyana, A, H., dan Silitonga, D, P. 1994. Tectonic Reversal In East Barito Basin, South Kalimantan. Indonesian Petroleum Association, Proceedings 23rd Annual Convention. Jakarta, Volume 1: 1-027.

Scott, C, A., dan Shah, T. 2004. Groundwater overdraft reduction through agricultural energy policy. insights from India and Mexico," International Journal of Water ResourcesDevelopment, Volume 4: 149-164.

Sihwanto dan Wahyudin. 2005. Konservasi Air Tanah Cekungan Air Tanahh Banjarmasin-Palangkaraya dan Cekungan Pagatan Provinsi Kalimantan Selatan. Direktorat Tata Lingkungan Geologi dan Kawasan Pertambangan: Bandung.

Sikumbang, N., dan Heryanto, R. 1994. Peta Geologi Lembar Kota Banjarmasin, Kalimantan, Skala 1:250.000, Pusat Penelitian dan Pengembangan Geologi: Bandung.

Todd, D, K. 1980. Groundwater Hydrology. John Willey and Sonc.inc: New York.

Wilcox, B, P., dan D.D. Breshears. 1995. Hydrology and Ecology Of Pinyon-Juniper Woodlands: Conceptual Framework And Field Studies. In Desired Future Conditions For Pinyon-Juniper Ecosystems. USDA Forest Service, Rocky Mountain Forest and Range Experiment Station. Flagstaff, AZ.

Young, D, B., Rosen, T., Fisher, T, R., Moorshead,T., dan Koslow, D. 2017. Dynamics of nitrate and methane in shallow groundwater following land use conversion from agricultural grain production to conservation easement. Agriculture, Ecosystems and Environment, Volume 248: 200-214.

Zekai, S. 2015. Practical and Applied Hydrogeology. Elsevier: Amsterdam. 